\title{
Biological Control of Collar Rot on Passion Fruits Via Induction of Apoptosis in the Collar Rot Pathogen by Bacillus subtilis
}

\author{
Yu-Hsuan Chen, Pei-Chun Lee, and Tzu-Pi Huang ${ }^{\dagger}$ \\ Department of Plant Pathology, National Chung-Hsing University, Taichung 40227, Taiwan \\ Accepted for publication 7 October 2020.
}

ABSTRACT

\begin{abstract}
The seedlings and fresh fruits of passion fruits are of high value in local and global trade. Fusarium solani is a main disease-causing agent affecting passion fruits. The objectives of this study were to develop Bacillus-based biocontrol agents for the management of Fusarium diseases on passion fruits and to investigate their putative control mechanisms. Our studies indicated that $B$. subtilis $\mathrm{YBC}$ and 151B1 show antagonistic activity to F. solani $\mathrm{PF} 7$ from passion fruits and inhibited the conidial germination of strain PF7. The application of broth cultures from B. subtilis 151B1 and YBC in SYB medium reduced disease severity of Fusarium wilt on the leaves of passion fruits and enhanced the survival rates of passion fruit seedlings challenged with $F$. solani PF7. With regard to the putative mechanisms of disease control, the results indicated that treatments consisting of the respective culture filtrates from $B$. subtilis 151B1 and YBC broths caused aberrant conidial morphology and loss of cell membrane integrity. Additionally, the treatments
\end{abstract}

caused reductions in mitochondrial membrane potential and interfered with the energy metabolism of $F$. solani PF7. The treatments also enhanced reactive oxygen species accumulation and resulted in the externalization of phosphatidylserine, chromatin condensation, and DNA fragmentation, suggesting their function in triggering apoptotic-like cell death. In conclusion, B. subtilis 151B1 and YBC are potential biocontrol agents for passion fruit disease caused by $F$. solani. Their control efficacy may result from the surfactins produced to trigger apoptotic-like cell death, reducing mitochondrial membrane potential and interfering with the energy metabolism of the pathogen.

Keywords: apoptosis, Bacillus subtilis, biocontrol, collar rot, disease control, energy metabolism, Fusarium solani, mitochondrial membrane potential, passion fruit, pest management
Passion fruit (Passiflora edulis) is widely grown in tropical and subtropical countries. In Taiwan, the main commercial variety of passion fruit is the Tainung No. 1 (P. edulis $\times$ P. edulis f.flavicarpa), which has high fruit quality and quantity (Agriculture and Food Agency 2018). Additionally, the grafted seedlings are of economic importance for the export market in Taiwan (Agriculture and Food Agency 2018). Diseases in passion fruit crops caused by phytopathogenic species of the Fusarium genus result in significant crop losses. Control strategies for these well-known soilborne diseases include the use of resistant rootstock, crop rotation, and fungicides; however, all of these strategies have limitations (Fischer and Rezende 2008; Khan et al. 2017; Ssekyewa et al. 1999). In Taiwan, $P$. edulis f. flavicarpa, which is considered to be relatively resistant to the Fusarium, is used as the grafting rootstock (Lee and Lin 2008; Martin and Nakasone 1970). However, there are currently no registered fungicides for Fusarium diseases in Taiwan and no available biological agents for the control of these diseases.

The utilization of microbial control agents in plant disease management has provided an effective, safe, and sustainable alternative for the control of Fusarium diseases (Khan et al. 2017). Bacillus species are well recognized as biocontrol agents against

${ }^{\dagger}$ Corresponding author: T.-P. Huang; tphuang@ nchu.edu.tw

Funding: This research was supported by grants from the Bureau of Animal and Plant Health Inspection and Quarantine, Council of Agriculture, Executive Yuan, Taiwan (108AS-14.2.2-BQ-B1(4) and 109AS-12.2.2-BQ-B1(4)), and the Ministry of Science and Technology, Executive Yuan, Taiwan (MOST 108-2321-B-005-006, MOST 108-2313-B-005-032, MOST 109-2313-B-005-032, and MOST 109-2321B-005-022)

*The $e$-Xtra logo stands for "electronic extra" and indicates that three supplementary figures are published online.

The author(s) declare no conflict of interest. various fungal diseases, including Fusarium infection (Khan et al. 2017; Ongena and Jacques 2008). Some B. subtilis strains have been shown to effectively control the diseases caused by $F$. solani on chili, tomatoes, potatoes, and beans (Abeysinghe 2007; Mnif et al. 2015; Sundaramoorthy et al. 2012). Interestingly, Sundaramoorthy et al. (2012) reported that combinations of B. subtilis strains EPCO16 and EPC5 and Pseudomonas fluorescens strain Pf1 showed greater protective effects against Fusarium disease in chili caused by $F$. solani than single agents. However, their control efficacy against collar rot in passion fruit is yet to be investigated.

Bacillus species influence plant and fungal pathogens through a number of mechanisms such as antagonizing pathogens by producing antibiotic metabolites, competing for essential nutrients, secreting enzymes, and inducing systemic resistance in plants (Choudhary and Johri 2009; Lugtenberg and Kamilova 2009; Ongena and Jacques 2008). The secondary metabolites from $B$. subtilis, such as surfactin, have been found to display antiproliferative effects against human colon carcinoma cells via the induction of apoptosis (Kim et al. 2007), whereas concentrations of fengycin produced by B. subtilis fmbJ of $<50 \mu \mathrm{g} / \mathrm{ml}$ were found to inhibit the growth of Rhizopus stolonifer and induce various apoptosis-associated markers, including reactive oxygen species (ROS) accumulation, mitochondrial membrane potential depolarization, chromatin condensation, phosphatidylserine externalization, and the occurrence of DNA strand breaks (Tang et al. 2014). In this study, we sought to develop Bacillus-based biocontrol agents isolated in rhizosphere soils in Taiwan for the management of collar rot disease caused by $F$. solani and attempted to reveal the molecular mechanisms underlying the Bacillus-Fusarium interaction.

\section{MATERIALS AND METHODS}

Bacterial strains, fungal isolates, and growth conditions. B. subtilis strains YBC and 151B1 were isolated from rhizosphere soils of banana plants grown in South District, Taichung City, and from tea plants grown in Mingian Township, Nantou County, 
Taiwan, respectively, according to the method described by Huang et al. (2012). To determine the species identity, strains YBC and 151B1 were subjected to physiological and biochemical characterization according to the methods described in Sneath et al. (1986) and using the Biolog system (Biolog Inc., Hayward, CA). The 16S rRNA sequence analysis used primers fD1 and rD1 according to the conditions described by Weisburg et al. (1991) and the gyrB sequence analysis used primers UP-1 and UP-2r according to the conditions described by Yamamoto and Harayama (1995). The genetic distances between sequences were estimated by the Kimura two-parameter method with the Dnadist program, Phylip version 3.6 (University of Washington, Seattle, WA). The phylogenetic tree based on $16 \mathrm{~S}$ rRNA and gyrB sequences was constructed by the neighbor-joining method (Neighbor program; Phylip version 3.6) and bootstrap analysis with 1,000 replicates was carried out using the Seqboot program (Phylip version 3.6).

Bacillus species and fungal strains were routinely cultured on potato sucrose agar (PSA), in which 1 liter of distilled water containing potato infusion from $200 \mathrm{~g}$ of sliced and boiled potato, $20 \mathrm{~g}$ of sucrose (Merck, Darmstadt, Germany), and $20 \mathrm{~g}$ of Bacto agar (Becton Dickinson, Franklin Lakes, NJ), adjusted to pH 7.0, at $30^{\circ} \mathrm{C}$ for the bacterial strains and at $25^{\circ} \mathrm{C}$ for the fungal isolates unless otherwise stated. B. subtilis $\mathrm{YBC}$ and $151 \mathrm{~B} 1$ were cultured in SYB broth at $30^{\circ} \mathrm{C}$ and $120 \mathrm{rpm}$ for 5 days using the procedure described by Huang et al. (2012).

The collar rot fungus was isolated from a symptomatic passion fruit. Isolate PF7 was subjected to species identification by morphological and cultural characterization and by sequence analysis using primers ITS1 and ITS4 for amplification of the internal transcribed spacer (ITS) region (White et al. 1990) and primers EF-1 and EF-2 for amplification of the partial elongation factor (EF)-1 $\alpha$ gene (Bueno et al. 2014). The amplification products were cloned using the Topo TA Cloning kit (Invitrogen Taiwan, Taipei, Taiwan) according to the manufacturer's instructions, and then sequenced at the Automated DNA Sequencing Service Laboratory at National Chung Chung-Hsing University in Taichung City, Taiwan. The sequence data were deposited in the GenBank database.

Pathogenicity assay of isolate PF7. Fungal isolate PF7 was subjected to a pathogenicity assay by artificial inoculation on the leaves, fruits, and grafted seedlings of passion fruit cultivar Tainung No. 1, for which P. edulis f. flavicarpa was used as the root stock. The leaves and fruits of the passion fruit were wound-inoculated with the conidial suspension of isolate PF7 at a concentration of $1 \times$ $10^{6}$ conidia $/ \mathrm{ml}$ in $0.1 \%$ water agar. The grafted seedlings of passion fruit cultivar Tainung No. 1 were inoculated with $10 \mathrm{ml}$ of the isolate PF7 conidial suspension at a concentration of $1 \times 10^{5}$ conidia $/ \mathrm{ml}$ by spraying the suspension on the soil used for the seedling cultivation.

Suppression of disease severity on passion fruit leaves. The preventive and curative effects of B. subtilis strains YBC and 151B1 against Fusarium disease were evaluated using a detachedleaf assay. Three milliliters of B. subtilis strain YBC and 151B1 culture broths at 100-fold dilution (final concentration of $10^{7} \mathrm{CFU} /$ $\mathrm{ml}$ ) were applied $3 \mathrm{~h}, 2$ days prior to, and 2 days after the inoculation with $F$. solani isolate PF7 (final concentration $1 \times 10^{4}$ conidia $/ \mathrm{ml}$ in $0.1 \%$ water agar) on the detached leaves of passion fruit cultivar Tainung No. 1. SYB medium and water were used as controls. Disease severity (DS) was determined using the following formula: DS $(\%)=[$ sum $($ index frequency $\times$ score of rating index $] /[$ (total number of inoculation sites $) \times($ maximal disease index $)] \times 100$, where rating index was scored on a 0 to 4 scale ( 0 , no symptoms; 1 , diameter of the necrotic lesion was $<2 \mathrm{~mm} ; 2$, diameter of the necrotic lesion ranged from 3 to $4 \mathrm{~mm}$; 3 , diameter of the necrotic lesion ranged from 5 to $6 \mathrm{~mm}$; or 4 , diameter of the necrotic lesion was $>7 \mathrm{~mm}$ ). Three leaves per treatment were used in the assay and the experiments were repeated three times.

Survival of passion fruit cuttings. Cuttings were taken from 3-week-old shoots of passion fruit cultivar Tainung No. 1. Each cutting had two internodal segments. The cuttings were dipped in 1,000 ppm of indole-3-butyric acid (Sigma-Aldrich, St. Louis, MO) for $5 \mathrm{~s}$; rooted in a potting mix composed of perlite, vermiculite, and peat moss (2:1:1); and infested with $F$. solani strain PF7 at a final concentration of $1 \times 10^{5}$ conidia/g. To assess the effects of $B$. subtilis strains 151B1 and YBC on survival of the passion fruit cuttings, the respective culture broths of 151B1 and YBC were diluted 100-fold to achieve a final concentration of $10^{9} \mathrm{CFU} / \mathrm{ml}$. Ten milliliters of each 100-fold diluted culture broth was spray-applied to each cutting in the Fusarium-infested potting mix. Treatments consisting of either water or SYB medium were used as controls. The experiments were conducted three times, with each treatment applied to three replicates and each replicate containing 15 cuttings. The survival rate of the cuttings was recorded at 1 month after treatment.

Conidial germination and penetration of $F$. solani PF7 on leaves of yellow passion fruit. B. subtilis culture filtrates were produced by centrifugation of the respective culture broths of strains 151B1 and YBC in SYB medium and then filtration of the supernatants through a $0.22-\mu \mathrm{m}$ filter (Millipore, Merck). To assess the effect of the culture filtrates from B. subtilis strains 151B1 and YBC on conidial germination of $F$. solani $\mathrm{PF7}$, the culture filtrates were applied at equal volume $(10 \mu \mathrm{l})$ to the conidial suspensions $\left(10^{5}\right.$ conidia/ml $)$ and then incubated at $25^{\circ} \mathrm{C}$. After $6 \mathrm{~h}$ of incubation, the percent germination rates were calculated by counting the geminated spores under a Leica DMLB microscope (Leica, Wetzlar, Germany). Additionally, the mixtures of culture filtrate and spores were inoculated on detached leaves of 1-monthold yellow passion fruit in a moisture chamber at $28^{\circ} \mathrm{C}$ for $12 \mathrm{~h}$ to determine the effect of $B$. subtilis culture filtrates on the formation of appressoria and penetration by $F$. solani PF7. Treatments consisting of water and SYB broth were used as controls. Treated conidia were stained with $10 \mu \mathrm{l}$ of $0.1 \%$ cotton blue (Merck) and examined with a Leica DMLB microscope.

Membrane integrity of $\boldsymbol{F}$. solani PF7. The respective culture filtrates from $B$. subtilis strains $151 \mathrm{~B} 1$ and YBC were produced as described above. Effects of $B$. subtilis strain 151B1 and YBC culture filtrates on the membrane integrity of $F$. solani PF7 were determined using a modified version of the method used by Chen and Dickman (2005). Briefly, each culture filtrate was applied at equal volume $(15 \mu \mathrm{l})$ to the conidial suspensions $\left(10^{5} \mathrm{conidia} / \mathrm{ml}\right)$ or the cells at $6 \mathrm{~h}$ postconidial germination, then incubated in a slide moisture chamber at $25^{\circ} \mathrm{C}$ for 3 or $6 \mathrm{~h}$. Treatment with SYB broth was used as a control. Treated conidia were stained with $10 \mu \mathrm{l}$ of $0.05 \%$ Evans blue for $45 \mathrm{~min}$ and examined with a Leica DMLB microscope.

Accumulation of ROS and induction of apoptotic-like cell death in $\boldsymbol{F}$. solani PF7. Accumulation of ROS in $F$. solani PF7 attributable to treatment with the respective culture filtrates from B. subtilis strains YBC and 151B 1 for $6 \mathrm{~h}$ was determined by staining the treated cells with dihydrorhodamine 123 and observing them with a fluorescent microscope (Leica) equipped with Optical Filter Set XF104-2 for yellow fluorescent protein (YFP; Omega Optical, Brattleboro, VT). Cells treated with SYB medium were used as a control. To test whether each culture filtrate would trigger apoptotic-like cell death in $F$. solani PF7, apoptotic features including DNA condensation and DNA fragmentation, as well as phosphatidylserine externalization, were examined (Chen and Dickman 2005). To assess the chromatin condensation of F. solani $\mathrm{PF} 7$, similar treatments for the determination of membrane integrity were used, except that treated conidia or geminated cells were stained with $10 \mu \mathrm{l}$ of $1 \mu \mathrm{g} / \mathrm{ml} \mathrm{4}$, 6-diamidino-2-phenylindole (DAPI; Sigma-Aldrich) for $10 \mathrm{~min}$ and examined with a fluorescent microscope equipped with the XF06 filter set (Omega Optical). To assay the externalization of phosphatidylserine of $F$. solani PF7, treated cells 3 or 4,6 , and $8 \mathrm{~h}$ post-treatment were stained with Annexin V-fluorescein isothiocyanate (FITC) and propidium iodide (PI) and observed with a fluorescent microscope equipped with the 
XF104-2 YFP filter (Omega Optical) for Annexin V-FITC and with green filter set 11002 (Chroma Technology Corp., Bellows Falls, VT) for PI. To determine the DNA fragmentation of $F$. solani PF7 treated with YBC and 151B1, cells that were treated for 3 or 4, 5, and $6 \mathrm{~h}$ were subjected to a terminal deoxynucleotidyl transferase dUTP nick end labeling (TUNEL) assay using an APoBrdU DNA Fragmentation Assay Kit (BioVision Inc., Milpitas, CA) and observed using a fluorescent microscope equipped with filter XF100-2 for green fluorescent protein (Omega Optical).

TABLE 1 . Optimized tandem mass spectrometry parameters by positive ionization mode for analysis of surfactin and iturin A family compounds

\begin{tabular}{lcccccc}
\hline Compound & $\mathrm{Q} 1(\mathrm{~m} / z)^{\mathrm{a}}$ & $\mathrm{Q} 3(\mathrm{~m} / z)$ & $\mathrm{DP}(\mathrm{V})$ & $\mathrm{EP}(\mathrm{V})$ & $\mathrm{CE}(\mathrm{V})$ & $\mathrm{CXP}(\mathrm{V})$ \\
\hline C14 surfactin & & & & & & \\
T1 & $1,023.0$ & 909.6 & 160 & 10 & 42.11 & 10 \\
T2 & $1,023.0$ & 685.7 & 160 & 10 & 42.09 & 10 \\
C15 surfactin & & & & & & \\
T1 & $1,037.0$ & 923.8 & 165 & 10 & 42.77 & 10 \\
T2 & $1,037.0$ & 685.7 & 165 & 10 & 43.84 & 10 \\
C14 iturinA & & & & & & \\
T1 & $1,044.0$ & 932.9 & 175 & 10 & 50 & 10 \\
T2 & $1,044.0$ & 638.6 & 175 & 10 & 50 & 10 \\
C15 iturin A & & & & & & \\
T1 & $1,058.0$ & 947.0 & 160 & 10 & 60 & 10 \\
T2 & $1,058.0$ & 652.0 & 160 & 10 & 55 & 10 \\
\hline
\end{tabular}

a $\mathrm{Q} 1$ = first quadrupole, $m / z=$ mass-to-charge ratio, $\mathrm{Q} 3=$ ion trap, $\mathrm{DP}=$ declustering potential, $\mathrm{EP}=$ entrance potential, $\mathrm{CE}=$ collision energy, $\mathrm{CXP}$ $=$ cell exit potential, $\mathrm{T} 1=$ first transition as a quantifier, and $\mathrm{T} 2=$ second transition as a qualifier.
Mitochondrial membrane potential of $F$. solani PF7. B. subtilis strains $151 \mathrm{~B} 1$ and YBC were respectively cultured in SYB broth at $30^{\circ} \mathrm{C}$ for 5 days, as previously described. One hundred microliters of each culture filtrate or water and $100 \mu \mathrm{l}$ of conidial suspension of $F$. solani PF7 $\left(10^{5}\right.$ conidia/ml $)$ were mixed together and incubated at $25^{\circ} \mathrm{C}$ for $12 \mathrm{~h}$. Conidia treated with SYB broth were used as a control. To monitor the mitochondrial membrane potential of $F$. solani PF7, treated conidia were stained with 5,5',6,6'-tetrachloro-1,1' $, 3,3^{\prime}$ '-tetraethylbenzimidazolocarbocyanine iodide (JC-1 dye; $20 \mu \mathrm{g} / \mathrm{ml}$ in $1 \%$ dimethyl sulfoxide; Life Technologies, Carlsbad, CA) using the method described by Reers et al. (1995) and examined with a fluorescent microscope equipped with the 11001v2 blue filter set (Chroma Technology Corp.).

Energy metabolism of $\boldsymbol{F}$. solani PF7. Effects of the respective $B$. subtilis strain $151 \mathrm{~B} 1$ and $\mathrm{YBC}$ culture filtrates on the energy metabolism of $F$. solani $\mathrm{PF} 7$ were determined using the method described by Cox et al. (2009). The respective culture filtrates from B. subtilis strains 151B1 and YBC in SYB broth or $202.8 \mu \mathrm{M}$ of pyraclostrobin, a fungicide known to block the transfer of electrons at the quinone outside site of the bc 1 complex (complex III in the electron transport chain) and in turn to block pathogens' ability to produce energy (Turner 2020), were applied at equal volume $(200 \mu \mathrm{l})$ to the conidial suspensions $\left(1 \times 10^{5}\right.$ conidia/ml $)$. Then, $180 \mu \mathrm{l}$ of the mixtures was loaded into 96 -well microplates. The mixtures were incubated in the dark at $25^{\circ} \mathrm{C}$ for $12 \mathrm{~h}$, then stained with Alamar blue for $1 \mathrm{~h}$. The color change of the Alamar blue owing to the corresponding degrees of redox reactions of F. solani PF7 was captured by a digital camera, and the relative fluorescent units with different treatments were examined with a
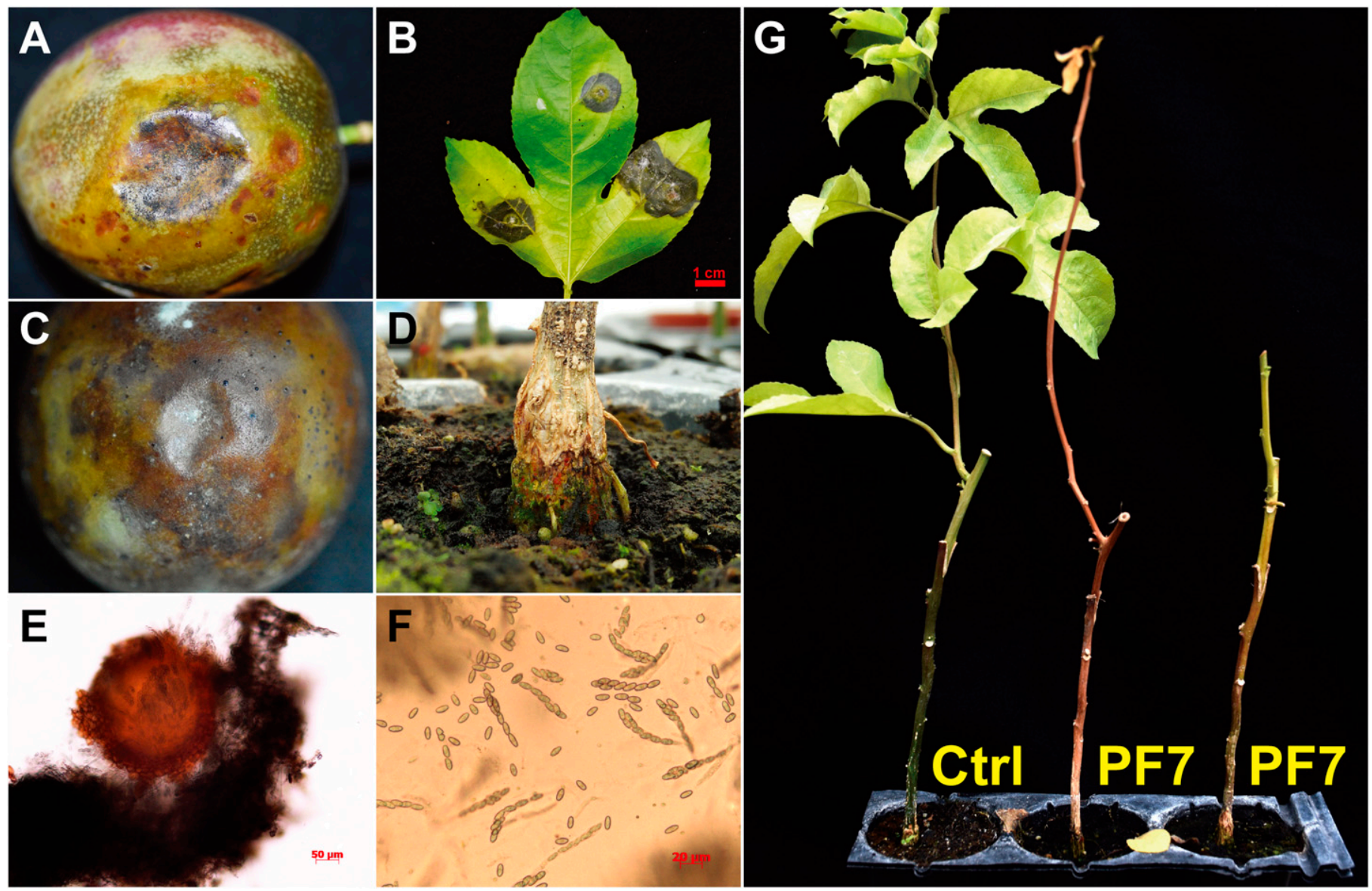

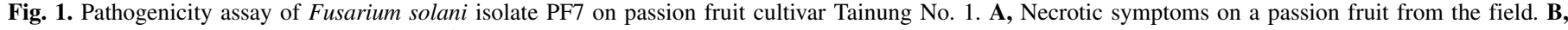

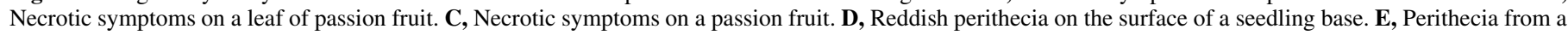

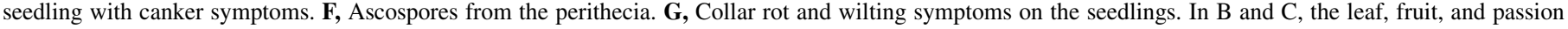
fruit seedlings were artificially inoculated with spore suspensions of isolate PF7. Ctrl = sterile distilled water used as a control. 
Tecan Infinite M200 plate reader (Tecan Austria GmbH, Grödig, Austria) with excitation at $570 \mathrm{~nm}$ and emission at $600 \mathrm{~nm}$.

Purification and analysis of lipopeptides. B. subtilis strains 151B1 and YBC were cultured in SYB broth as described above. The culture supernatant was collected and filtered with a $0.22-\mu \mathrm{m}$ filter (Millipore). The filtrates were directly subjected to or diluted 10 -fold with methanol (Merck) for iturin or surfactin analysis, respectively, using liquid chromatography (LC)-tandem mass spectrometry (MS/MS; AB Sciex QTRAP5500; AB Sciex Pte. Ltd., Taipei, Taiwan). Two microliters of each sample was applied to a high-performance LC system (1200 Infinity; Agilent Technologies) on a C18 reverse-phase CORTECS UPLC T3 column $(2.1 \times 100 \mathrm{~mm}, 1.6 \mu \mathrm{m}$ particle size; Waters, Taipei, Taiwan). Separation was performed with the following gradient:
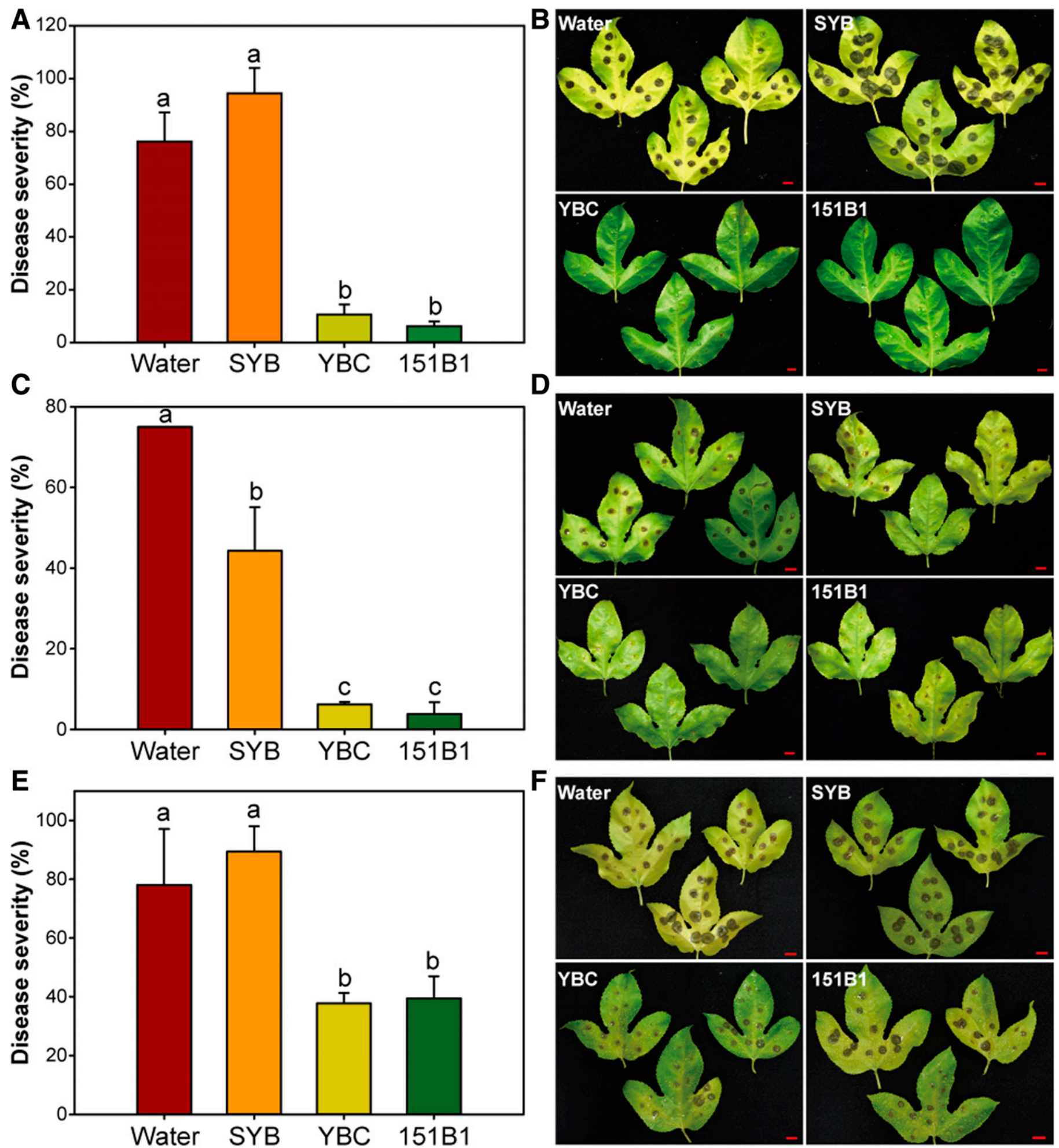

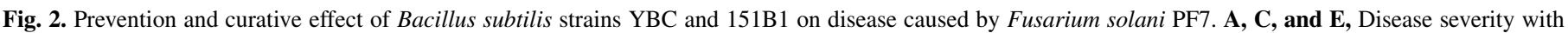

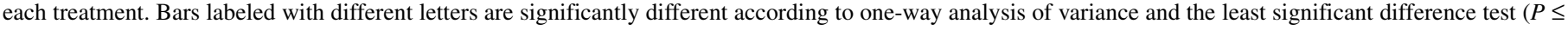

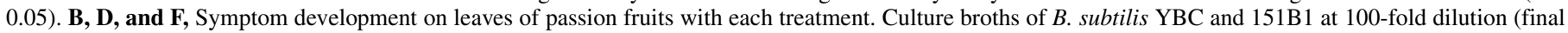

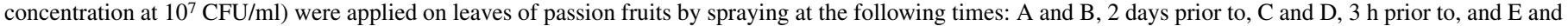
F, 2 days after inoculation with $F$. solani PF7. Water and SYB medium were used as controls. Bars $=1 \mathrm{~cm}$. 
$98 \%$ mobile phase A consisting of $0.1 \%$ (vol/vol) formic acid and $5 \mathrm{mM}$ of ammonium acetate in water, and $2 \%$ mobile phase B consisting of $5 \mathrm{mM}$ of ammonium acetate in methanol (Merck) for $3.5 \mathrm{~min}, 50$ to $100 \%$ mobile phase B for $15.5 \mathrm{~min}$, and $100 \%$ mobile phase $\mathrm{B}$ for $3 \mathrm{~min}$ at a flow rate of $0.3 \mathrm{ml} / \mathrm{min}$. The surfactin or iturin family compounds were detected by electrospray ionization MS in positive mode using multiple reaction monitoring (MRM) with the following parameters: curtain gas flow at $15 \mathrm{psi}$, high collision gas, ion-spray voltage of $5,500 \mathrm{~V}$, source temperature of $350^{\circ} \mathrm{C}$, and ion source gas 1 and 2 at 55 psi. The MS/MS parameters (declustering potential, collision energy, and collision cell exit potential) were optimized using the surfactin from B. subtilis (Sigma-Aldrich) and iturin A from B. subtilis (Sigma-Aldrich) as standards (Table 1).

Statistical analysis. All experiments were performed at least three times. The data are presented as means and standard deviations obtained from at least three replicates of a representative experiment. Significant differences between the treatments were determined by one-way analysis of variance and the least significant difference test using SPSS 15.0 software (SPSS Inc., Chicago, IL).

Nucleotide sequence accession numbers. The $16 \mathrm{~S}$ rRNA sequences of native Bacillus strains 151B1 and YBC were deposited in the GenBank database under accession numbers MN900849 and MN900851. The gyrB sequences of strains 151B1 and YBC were deposited in GenBank under accession numbers MT711973 and MT711974, respectively. Sequences of the ITS regions and partial EF- $1 \alpha$ gene of $F$. solani isolate PF7 were also deposited in GenBank under accession numbers MN904856 and MN911171, respectively.

\section{RESULTS}

Collar rot fungus of passion fruit. Fungal strain PF7 was isolated from a fruit of passion fruit cultivar Tainung No. 1 with necrotic symptoms. Artificial inoculation of strain PF7 on the leaves, fruits, and grafted seedlings of passion fruit cultivar Tainung No. 1 caused necrotic symptoms on leaves and fruits, chlorosis and shedding of leaves, dieback of branches, and plant death, outcomes similar to those observed for symptomatic leaves and fruits collected from the field (Fig. 1A, B, and C). Additionally, after 4 months of inoculation, collar rot symptoms appeared in the stem above the soil level, and perithecia and ascospores were formed in the cracks of the collar rot regions (Fig. 1D, E, and F).

Strain PF7 was single-spore isolated and cultured on PSA at $25^{\circ} \mathrm{C}$. The strain PF7 colony was creamy white to yellowish in color. PF7 produced long phialides with a length of $68.9 \pm 14.7 \mu \mathrm{m}$, macroconidia with a mean size of $25.8 \pm 3.2 \times 5.2 \pm 0.9 \mu \mathrm{m}$ and three to four seta, oval microconidia with a mean size of $8.7 \pm 1.6 \times 3.8 \pm 0.5 \mu \mathrm{m}$, and chlamydospores similar to those of $F$. solani as described by previous studies (Bahar and Shahab 2012; Bueno et al. 2014; Leslie and Summerell 2008) (data not shown). Sequences of the ITS regions and partial EF-1 $\alpha$ gene from strain PF7 were analyzed and deposited in the GenBank database under accession numbers MN904856 and MN911171, respectively. Phylogenetic trees of the ITS regions and EF-1 $\alpha$ gene showed that strain PF7 is within the $F$. solani species complex group (data not shown). Based on its morphological and molecular characteristics, strain PF7 was identified as F. solani.

Effect of $B$. subtilis on suppression of Fusarium disease. Two $B$. subtilis strains, 151B1 and YBC, were isolated from native rhizosphere soil and identified majorly based on biochemical and physiological characteristics according to the methods described in Sneath et al. (1986) and using the Biolog system. The 16s rRNA and gyrB sequences were deposited in the GenBank database under the above-mentioned accession numbers. The phylogenetic analysis of 16s rRNA and $g y r B$ genes is provided in Supplementary Figure S1. To evaluate the potential for applying $B$. subtilis strains YBC and 151B1 for control of collar rot disease in passion fruit caused by F. solani, a detached-leaf inoculation system was used because of the long duration of symptom development for collar rot. The results showed that the application of the respective culture broths of
B. subtilis $\mathrm{YBC}$ and $151 \mathrm{~B} 1$ at 2 days prior to inoculation with F. solani $\mathrm{PF} 7$ reduced DS to $10.6 \pm 3.8 \%$ and $6.1 \pm 1.9 \%$, respectively, severity levels which were much lower than those for the water $(76.1$ $\pm 11.1 \%)$ and SYB medium $(94.4 \pm 9.6 \%)$ controls. Application of the respective culture broths of $B$. subtilis $\mathrm{YBC}$ and $151 \mathrm{~B} 1$ at $3 \mathrm{~h}$ prior to inoculation with strain PF7 reduced DS to $6.2 \pm 0.6 \%$ and $3.8 \pm$ $2.9 \%$, respectively, levels which were also much lower than those for the water $(75.0 \pm 0.0 \%)$ and SYB medium $(44.3 \pm 10.8 \%)$ controls. Finally, application of the respective culture broths of $B$. subtilis YBC and 151B1 2 days after challenge with strain PF7 reduced DS to 37.8 $\pm 3.5 \%$ and $39.4 \pm 7.5 \%$, respectively, levels which were likewise much lower than those for the water $(78.0 \pm 19.1 \%)$ and SYB medium $(89.4 \pm 8.6 \%)$ controls (Fig. 2). The data thus suggested that B. subtilis strains YBC and 151B1 exhibited protective and curative efficacy in terms of suppression of Fusarium disease on passion fruit plants. Additionally, the respective culture broths of B. subtilis strains YBC and 151B1 diluted by 100-fold and applied on the day of planting and once per week for 4 weeks on passion fruit cuttings in the Fusarium-infested potting mix significantly enhanced the survival rates of the passion fruit cuttings (Fig. 3).

Effect of the respective culture filtrates from $B$. subtilis strains YBC and 151B1 on conidial germination of $F$. solani PF7. To determine whether suppression of Fusarium disease on passion fruit plants was attributable to the inhibition of conidial
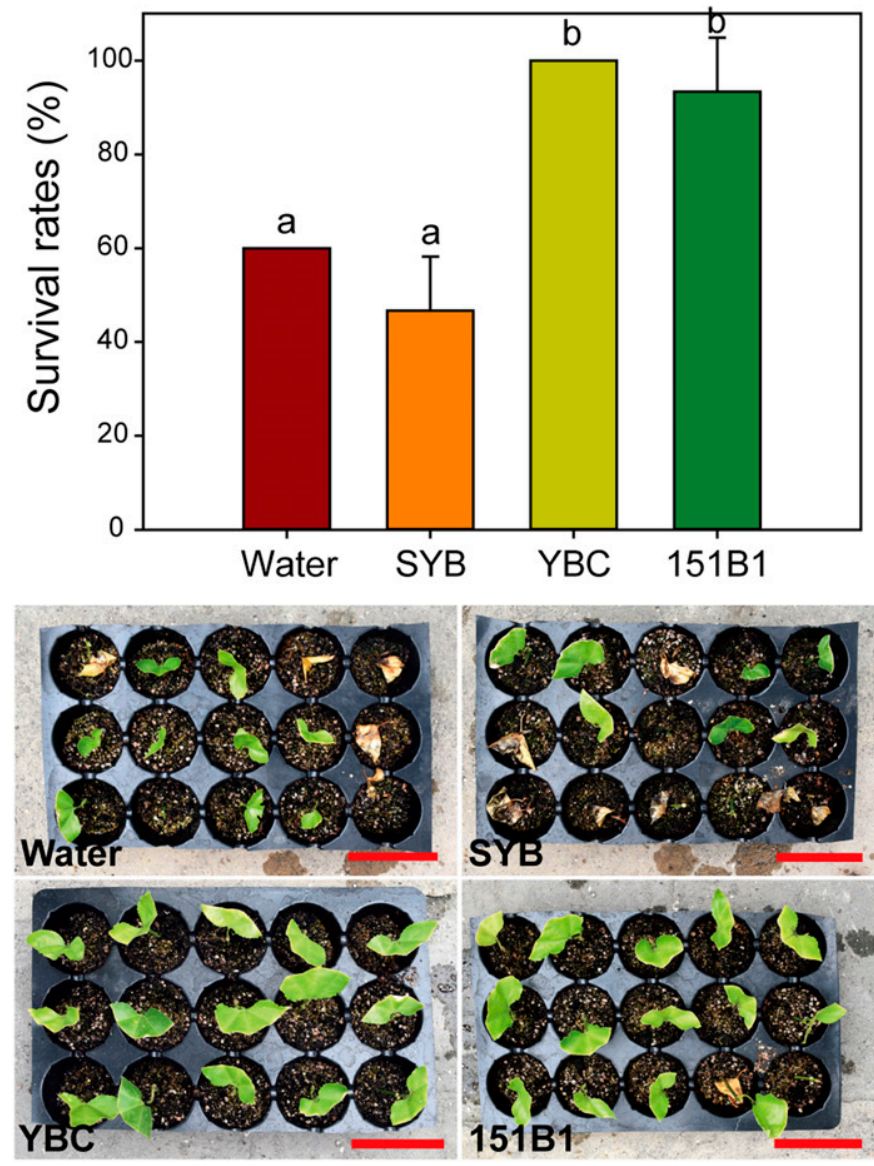

Fig. 3. Effects of Bacillus subtilis strains YBC and 151B1 on survival of passion fruit cuttings in Fusarium-infested potting mix. Passion fruit cultivar Tainung No. 1 was used in this study. B. subtilis strains YBC and 151B1 were respectively cultured in SYB broth at $30^{\circ} \mathrm{C}$ for 5 days. Ten milliliters of each culture broth diluted by 100 -fold (to a final concentration of $10^{7} \mathrm{CFU} / \mathrm{ml}$ ) was applied on the cuttings by spraying on each cutting once per week for 4 weeks. Data are presented as means and standard deviations from 15 replicates in a representative experiment. Bars labeled with different letters are significantly different according to one-way analysis of variance and the least significant difference test $(P \leq 0.05)$. Water and SYB broth were used as controls. Bars $=$ $10 \mathrm{~cm}$. 
germination of the pathogen by B. subtilis strains YBC and 151B1, culture filtrates from the two strains were assessed for their effects on conidial germination rates of $F$. solani $\mathrm{PF} 7$ and the colonization and infection on leaves of cultivar Tainung No. 1 by F. solani PF7.
The results indicated that culture filtrates from $B$. subtilis strains YBC and 151B1 significantly inhibited spore germination and mycelium growth of $F$. solani $\mathrm{PF} 7$ and caused swelling of the germ tubes and hyphal tips (Fig. 4A and B; Supplementary Fig. S3).
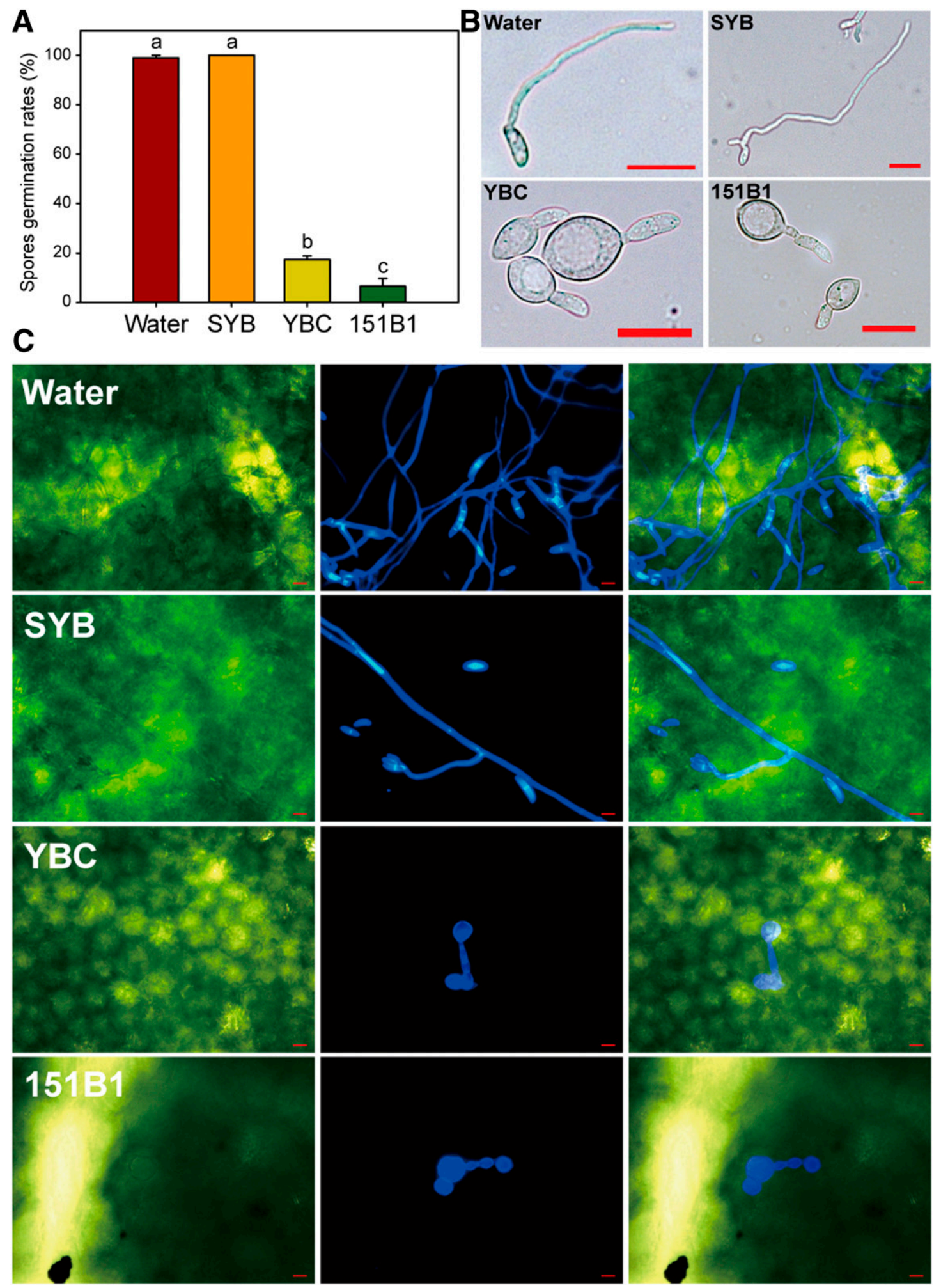

Fig. 4. Effects of culture filtrates from Bacillus subtilis strains $\mathrm{YBC}$ and 151B1 on conidial germination of Fusarium solani PF7. A, Conidial germination rates of F. solani PF7. B, Conidial morphology under a microscope with each treatment. Ten microliters of the culture filtrate from $B$. subtilis $\mathrm{YBC}$ or $151 \mathrm{~B} 1$ and $10 \mu 1$ of $F$. solani PF7 conidial suspension $\left(10^{5} \mathrm{conidia} / \mathrm{ml}\right)$ were mixed together on a glass slide and incubated at $25^{\circ} \mathrm{C}$ for $6 \mathrm{~h}$. The conidial germination rate was calculated as follows: Conidial germination rate $(\%)=($ numbers of germinated conidia/100 $) \times 100$. Data are presented as means and standard deviations from three replicates. Bars labeled with different letters are significantly different according to one-way analysis of variance and the least significant difference test $(P \leq 0.05)$. C, Colonization and infection on leaves of cultivar Tainung No. 1 by $F$. solani isolate PF7 with each treatment. Equal volumes of $B$. subtilis and $F$. solani PF7 culture suspensions were mixed together and spotted on a detached leaf of passion fruit, then incubated at $25^{\circ} \mathrm{C}$ for $12 \mathrm{~h}$. F. solani PF7 was stained with mixtures of Calcofluor white M2R and Evans blue in $10 \% \mathrm{KOH}$ and observed with a Leica DMLB microscope. Bars $=20 \mu \mathrm{m}$. 
Germination rates after treatments with culture filtrates from B. subtilis strains YBC and 151B1 were $17.3 \pm 1.5 \%$ and $6.7 \pm 3.1 \%$, respectively, which were much lower than rates for the water and SYB medium controls $(99.0 \pm 1.0 \%$ and $100.0 \pm 0.0 \%$, respectively; Fig. 4A). After treatments with water and SYB medium, the conidia of $F$. solani PF7 germinated, formed mycelia, colonized, and penetrated into the leaves of the passion fruit plants; after treatments with the culture filtrates from B. subtilis strains YBC and 151B1, germination of spores was inhibited and abnormal and swollen germ tubes were observed (Fig. 4C).

Effects of the respective culture filtrates from $B$. subtilis strains YBC and 151B1 on membrane integrity of $F$. solani PF7. To assess whether the metabolites produced by $B$. subtilis strains YBC and 151B1 disrupt the membrane integrity of F. solani PF7 and result in abnormal and swollen morphology of germ tubes and inhibition of conidial germination, the conidia of $F$. solani $\mathrm{PF} 7$ treated with $\mathrm{SYB}$ medium and the respective culture filtrates of B. subtilis strains YBC and 151B1 were stained with Evans blue and examined using a Leica DMLB microscope. The results showed that after $6 \mathrm{~h}$ of conidial germination treated with the culture filtrates of $B$. subtilis strains YBC and 151B1, F. solani PF7 conidia and cells were permeated by Evans blue dye 3 and $6 \mathrm{~h}$ post-treatment, whereas cells treated with SYB medium excluded the dye (Fig. 5; Supplementary Fig. $\mathrm{S} 3$ ), suggesting that the cell membrane integrity of $F$. solani PF7 was affected by the metabolites produced by B. subtilis strains YBC and 151B1.

Effects of the respective culture filtrates from $B$. subtilis strains YBC and 151B1 on accumulation of ROS and induction of apoptotic-like cell death in $F$. solani PF7. To examine whether the metabolites produced by B. subtilis strains YBC and 151B1 induce accumulation of ROS in F. solani PF7 and lead to apoptotic-like cell death in $F$. solani PF7, the cellular accumulation of ROS and apoptotic features, including DNA condensation, DNA fragmentation, and phosphatidylserine externalization (Chen and Dickman 2005), were tested for cells of $F$. solani $\mathrm{PF} 7$ treated with the culture filtrates from $B$. subtilis strains YBC and 151B1. Cells treated with SYB medium were used as controls. After each treatment was applied for $6 \mathrm{~h}$, green fluorescence was observed in the cells treated with the culture filtrates from B. subtilis strains YBC and 151B1 but not in the cells treated with SYB medium, suggesting that the accumulation of ROS was induced by the culture filtrates from B. subtilis strains YBC and 151B1 (Fig. 6A). We also observed FITC-Annexin V binding to the fungal cells treated with the culture filtrates from $B$. subtilis strains YBC and 151B1 but no staining in SYB medium-treated cells, indicating that the externalization of phosphatidylserine was caused by the culture filtrates from B. subtilis strains YBC and 151B1 (Fig. 6B). Notably, FITC-Annexin V was found to bind to fungal cells after $4 \mathrm{~h}$ or to cells at $6 \mathrm{~h}$ postgermination after $3 \mathrm{~h}$ of treatment with the culture filtrates from B. subtilis strains YBC and 151B1; however, such binding of PI and DNA fragmentation assessed by the TUNEL assay were not observed, suggesting the occurrence of early apoptosis after $4 \mathrm{~h}$ of treatment (Supplementary Figs. S2 and S3). The treatments were assessed with DAPI staining assays to visualize the resulting DNA and nuclear morphology, and we found that $F$. solani PF7 cells treated with the culture filtrates from B. subtilis strains YBC and 151B1 showed diffuse nuclear staining indicating chromatin fragmentation, whereas SYB medium-treated cells displayed compact single nuclei (Fig. 6C). DNA fragmentation was detected in situ by the TUNEL assay, and strong TUNEL staining was observed in $F$. solani PF7 cells treated with the culture filtrates from B. subtilis YBC and 151B1 strains for $6 \mathrm{~h}$ (Fig. 6D; Supplementary Fig. S3). However, no such staining was observed in SYB medium-treated cells (Fig. 6D). These results suggested that the metabolites produced by B. subtilis strains YBC and 151B1 induced the accumulation of ROS and triggered apoptosis in F. solani PF7.
Effects of the respective culture filtrates from $B$. subtilis strains YBC and 151B1 on mitochondrial membrane potential and energy metabolism of $F$. solani PF7. As the above results indicated that the metabolites produced by $B$. subtilis strains YBC and 151B1 disrupted the membrane integrity of F. solani $\mathrm{PF} 7$, the effects of B. subtilis strains YBC and 151B 1 on the membrane potential and energy metabolism of $F$. solani $\mathrm{PF} 7$ were assayed by cytofluorimetric analysis using JC-1 staining (Reers et al. 1995) and the Alamar blue assay (Cox et al. 2009), respectively. The hyphal tip of an SYB medium-treated cell showed an orange to red color after JC-1 staining, whereas the cells treated with the culture filtrates from B. subtilis strains YBC and 151B1 exhibited a green color after JC-1 staining, suggesting that the culture filtrates from B. subtilis strains YBC and 151B1 caused reductions in the mitochondrial membrane potential of $F$. solani PF7 (Fig. 7).

For the Alamar blue assay, blue nonfluorescent dye in the conidial suspensions of $F$. solani $\mathrm{PF} 7$ treated with SYB medium was reduced to the pink-colored, highly fluorescent resorufin, whereas the dye in the conidial suspensions of $F$. solani PF7 treated with the culture filtrates from B. subtilis strains YBC and 151B1 remained a blue to dark purple color and exhibited significantly lower relative fluorescent units than after treatment with SYB medium (Fig. 8). The color of the dye following treatments with the culture filtrates from B. subtilis strains YBC and 151B1 was similar to that for a known respiration quinone outside inhibitor, pyraclostrobin (Fig. 8 ). These results suggested that interference with the energy metabolism of $F$. solani $\mathrm{PF7}$ is caused by the metabolites produced by B. subtilis strains YBC and 151B1.

Lipopeptides produced by $B$. subtilis strains YBC and 151B1. The above results indicated that the culture filtrates from B. subtilis strains YBC and 151B1 exhibited the effect of triggering apoptotic-like cell death, reduced mitochondrial membrane potential, and interfered with the energy metabolism of $F$. solani PF7. The metabolites produced by these two strains were analyzed by LCMS/MS. The chromatogram for surfactins and iturin A standards showed that the main peaks of C14 surfactin, C15 surfactin, C14 iturin $\mathrm{A}$, and $\mathrm{C} 15$ iturin $\mathrm{A}$ were eluted at retention times 17.5, 17.7, 10.1, and $11.0 \mathrm{~min}$, respectively (Fig. 9A, B, C, and D). The MRM transitions for qualification were $1,023.0$ to 685.7 for $\mathrm{C} 14$ surfactin, 1,036.0 to 685.7 for $\mathrm{C} 15$ surfactin, 1,044.0 to 638.6 for C14 iturin A, and 1,058.0 to 652.0 for $\mathrm{C} 15$ iturin A (Fig. 9E, F, G, and H; Table 1).

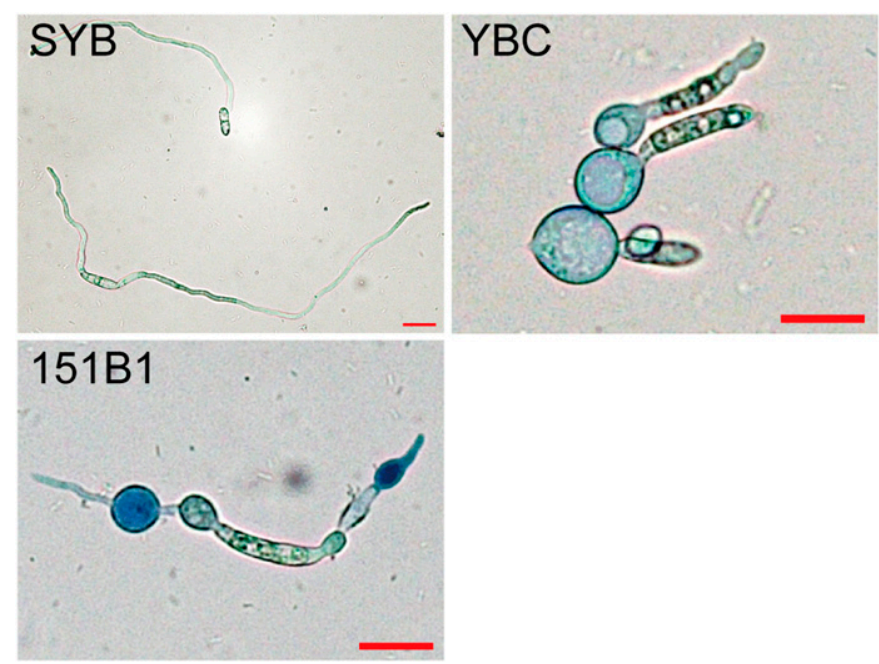

Fig. 5. Effects of culture filtrates from Bacillus subtilis strains YBC and 151B1 on the membrane integrity of Fusarium solani PF7. Equal amounts of SYB medium, B. subtilis YBC culture filtrate, or B. subtilis $151 \mathrm{~B} 1$ culture filtrate were mixed with $F$. solani $\mathrm{PF} 7$ conidial suspensions $\left(1 \times 10^{5}\right.$ conidia/ $\mathrm{ml}$ ) and then incubated at $25^{\circ} \mathrm{C}$ for $6 \mathrm{~h}$. Cells of $F$. solani PF7 treated with each treatment were stained with Evans blue for $45 \mathrm{~min}$ and examined using a Leica DMLB microscope. Bars $=20 \mu \mathrm{m}$. 
The MRM transitions for quantification were 1,023.0 to 909.6 for C14 surfactin, $1,037.0$ to 923.8 for C15 surfactin, 1,044.0 to 932.9 for C14 iturin A, and 1,058.0 to 947.0 for C15 iturin A (Fig. 9E, F, G, and $\mathrm{H}$; Table 1). Both B. subtilis strains 151B1 and YBC produced surfactin family compounds, and the chromatograms are shown in Figure 9I and J, respectively. The concentrations produced by strains $151 \mathrm{~B} 1$ and YBC were $31.7 \pm 3.0$ and $8.7 \pm 1.0 \mathrm{mg} / \mathrm{liter}$ related to C14-surfactin standard and $15.1 \pm 1.4$ and $13.5 \pm 2.3 \mathrm{mg} /$ liter related
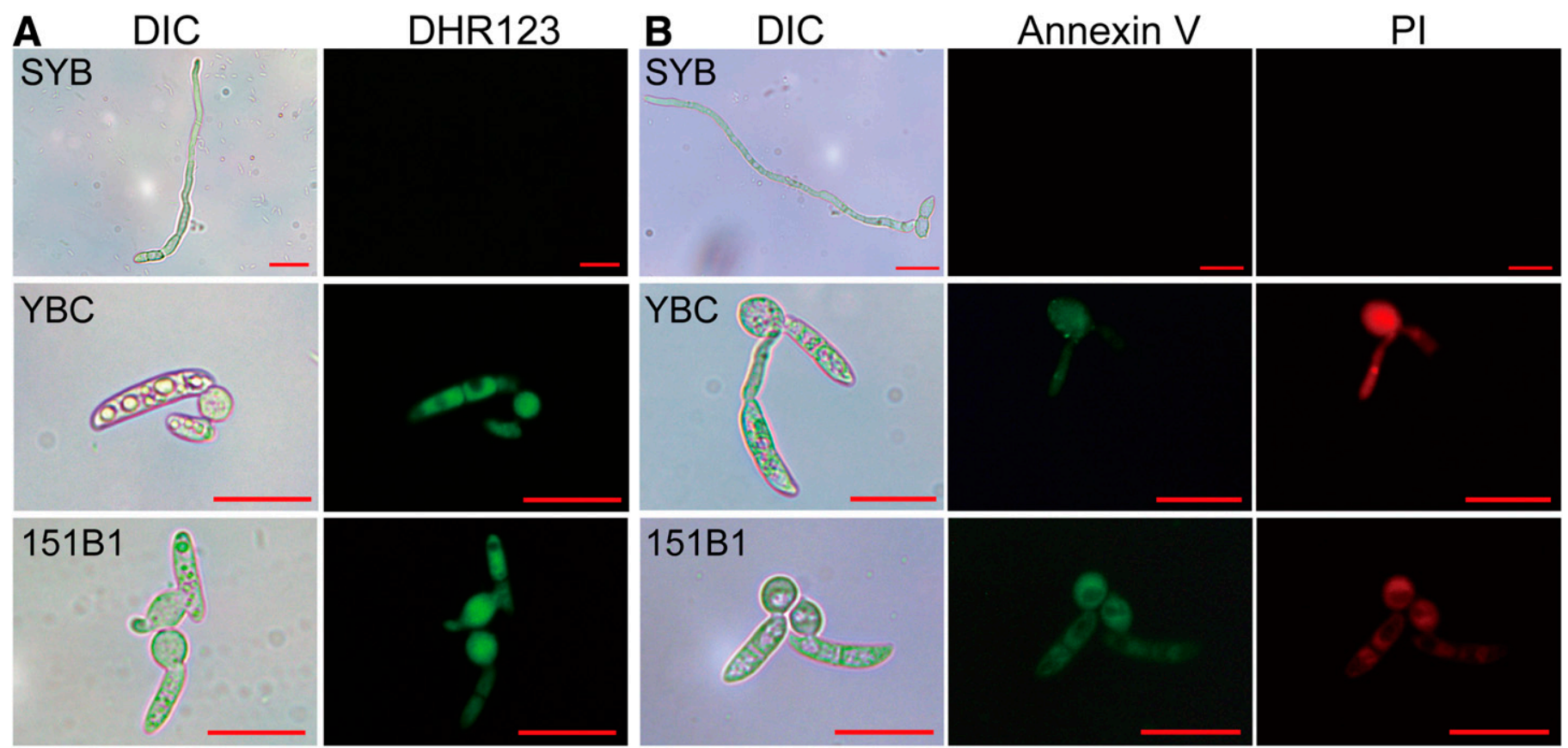
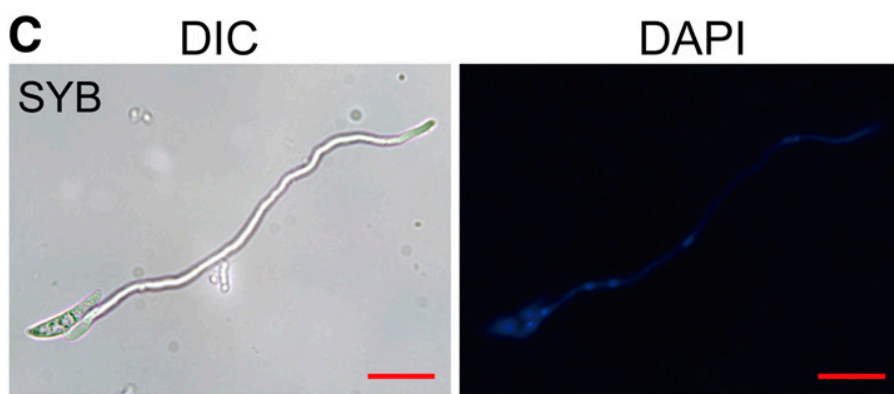

D
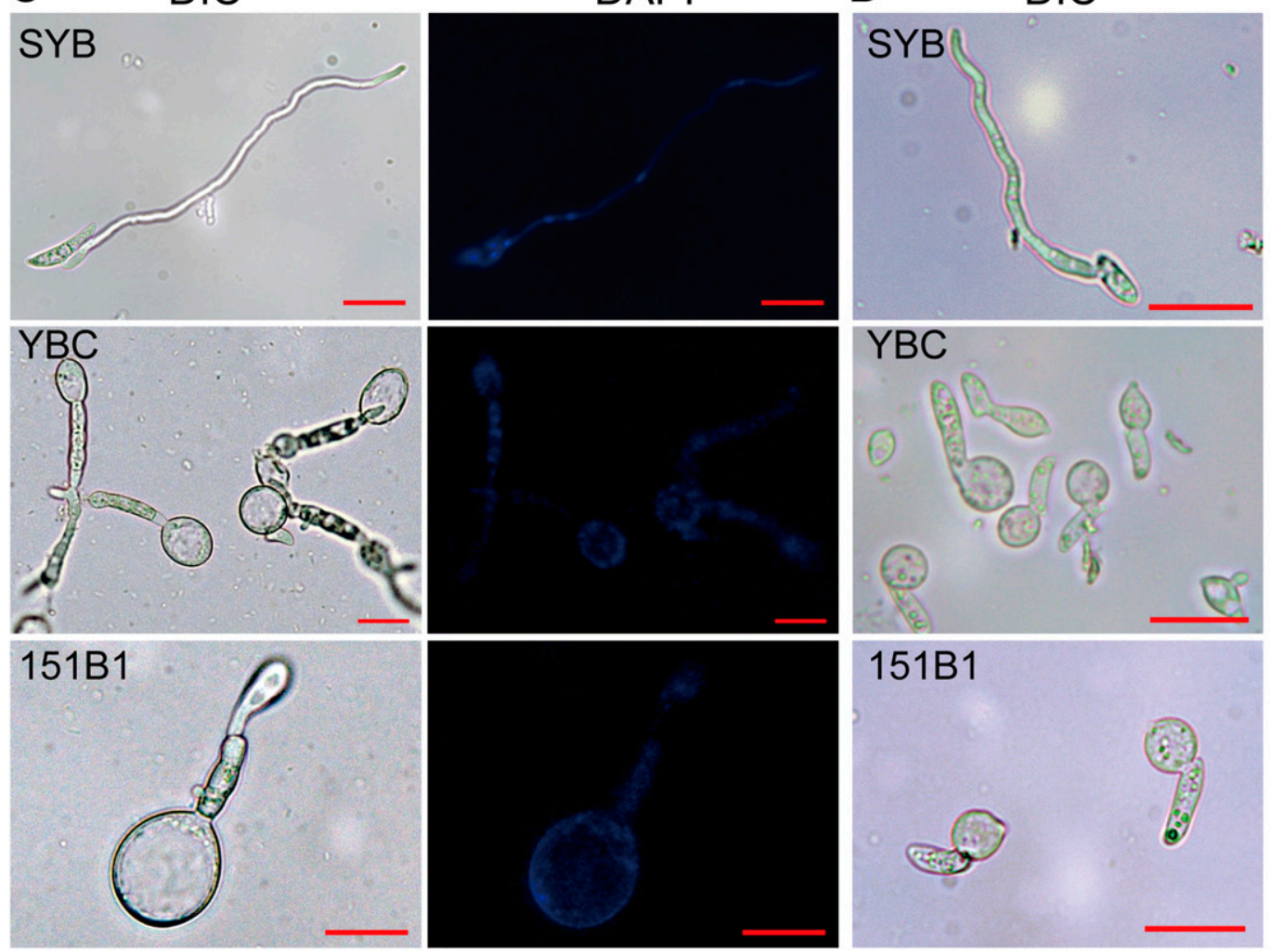
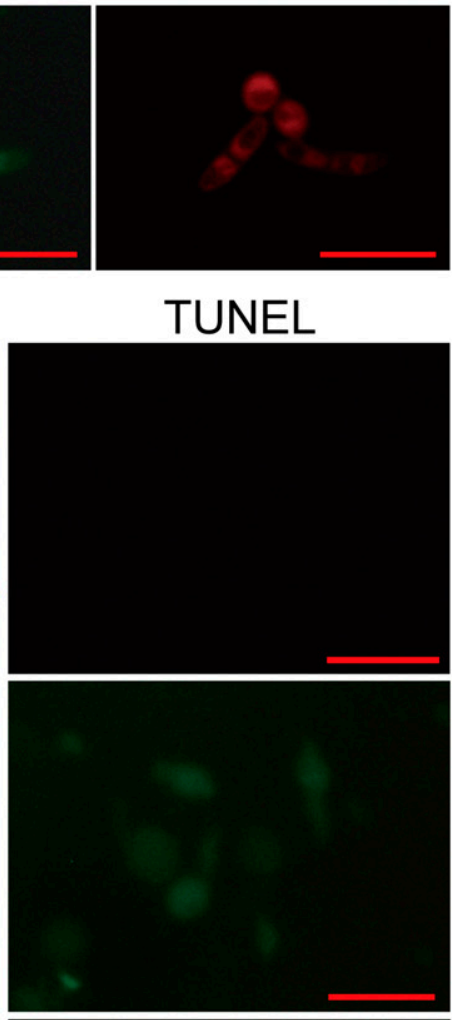

Fig. 6. Effects of culture filtrates from Bacillus subtilis strains YBC and 151B1 on the accumulation of reactive oxygen species and the induction of apoptotic-like cell death in Fusarium solani PF7. A, Accumulation of reactive oxygen species in F. solani isolate PF7 treated with culture filtrates from B. subtilis YBC and 151B1 for $6 \mathrm{~h}$. SYB medium was used as a control. Cells were stained with dihydrorhodamine 123 and observed with a fluorescent microscope (Leica) equipped with Optical Filter Set XF104-2 for yellow fluorescent protein (YFP; Omega Optical). B, Externalization of phosphatidylserine of $F$. solani PF7 treated with YBC and 151B1. Treated cells were stained with Annexin V-fluorescein isothiocyanate (FITC) and propidium iodide (PI) and observed with a fluorescent microscope equipped with filter XF104-2 YFP (Omega Optical) for Annexin V-FITC and with green filter set 11002 (Chroma Technology) for PI. C, Chromatin condensation of $F$. solani PF7 treated with YBC and 151B1 for $4 \mathrm{~h}$. Treated cells were stained with 4',6-diamidino-2-phenylindole (DAPI) and observed using a fluorescent microscope equipped with Optical Filter Set XF06 (Omega Optical). D, DNA fragmentation of $F$. solani PF7 treated with YBC and $151 \mathrm{~B} 1$ for 6 h. Treated cells were subjected to a terminal deoxynucleotidyl transferase dUTP nick end labeling (TUNEL) assay and observed using a fluorescent microscope equipped with filter XF100-2 for green fluorescent protein (Omega Optical). DIC $=$ differential interference contrast. Bars $=20 \mu \mathrm{m}$. 
to C15-surfactin standard, respectively. Although only strain 151B1 produced iturin A family compounds (Fig. 9K), the concentration was $16.6 \pm 0.3 \mathrm{mg} /$ liter relative to C14-iturin A and $6.5 \pm 0.2 \mathrm{mg} / \mathrm{liter}$ relative to $\mathrm{C} 15$-iturin $\mathrm{A}$.

\section{DISCUSSION}

Fusarium diseases that occur on passion fruits include collar rot and Fusarium wilt. The former is caused by F. solani [teleomorph: Neocosmospora solani (Martius) L. Lombard \& Crous], and the latter is caused by $F$. oxysporum f. sp. passiflorae (Fischer and Rezende 2008). In this study, we isolated one Fusarium strain (PF7) from symptomatic passion fruits, and we artificially inoculated grafted seedlings of passion fruit cultivar Tainung No. 1, for which $P$. edulis f. flavicarpa was used as the root stock, with strain PF7 to induce typical collar rot symptoms. After 4 months of inoculation, collar rot symptoms, including perithecia and ascospores, appeared at the stem of the root stock. Macroconidia of strain PF7 were relatively wide and stout with rounded ends, and microconidia were formed in false heads on long monophialides with morphological characteristics similar to those of $F$. solani but different from those of F. oxysporum (Leslie and Summerell 2008). According to the phylogenetic analyses of the ITS regions and EF- $1 \alpha$ gene sequences, strain PF7 belongs to the $F$. solani species complex and is distant from the F. oxysporum species complex. Interestingly, the ITS regions and EF- $1 \alpha$ gene sequences of strain PF7 exhibited higher sequence identity to those of $F$. solani $\mathrm{f}$. sp. radicicola from carrot hosts (99.8\% identity to GenBank accession AY819045 and $99.0 \%$ to AB513841) (Honraet et al. 2005) than to that of $F$. solani $\mathrm{f}$. sp. passiflorae isolate IBFS11 from passion fruit (94.9\% identity to GenBank accession JX524771). Thus, strain PF7 was identified as F. solani.

Bacillus species have previously been shown to suppress Fusarium diseases (Sarwar et al. 2018; Swain et al. 2008; ZalilaKolsi et al. 2016). The use of a combination of the compatible B. amyloliquefaciens strain BLB369, B. subtilis strain BLB277, and Paenibacillus polymyxa strain BLB267 resulted in the highest control of Fusarium head blight by Fusarium graminearum compared with the strains used individually (Zalila-Kolsi et al. 2016). The purified surfactin A from B. subtilis strain NH-100 and Bacillus sp. strain NH-217 cultured in Luria-Bertani medium had

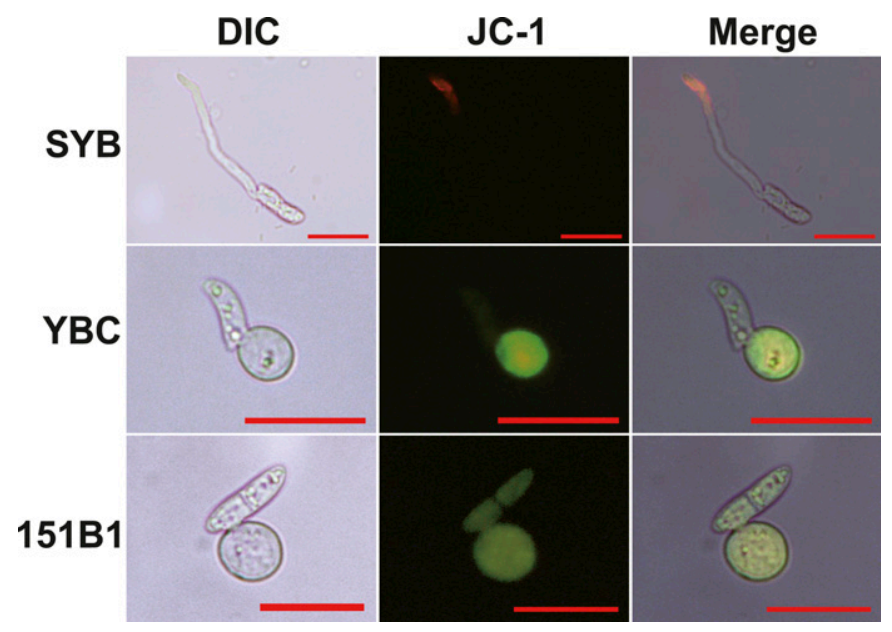

Fig. 7. Effects of culture filtrates from Bacillus subtilis strains YBC and 151B1 on mitochondrial membrane potential of Fusarium solani PF7. Equal amounts of SYB medium, B. subtilis YBC culture filtrate, or B. subtilis 151B1 culture filtrate were mixed with $F$. solani $\mathrm{PF} 7$ conidial suspensions $\left(1 \times 10^{5}\right.$ conidia/ml) and then incubated at $25^{\circ} \mathrm{C}$ for $6 \mathrm{~h}$. Treated cells were stained with $5,5^{\prime}, 6,6^{\prime}$-tetrachloro-1,1',3,3'-tetraethylbenzimidazolocarbocyanine iodide (JC-1) and observed with a differential interference contrast (DIC) microscope and a fluorescent microscope equipped with filter C-9485. Bars $=20 \mu \mathrm{m}$. strong antifungal activity against $F$. oxysporum, $F$. moniliforme, and $F$. solani and significantly reduced rice bakanae disease by up to $80 \%$ (Sarwar et al. 2018). An in vivo study suggested that B. subtilis strains CM1 and CM3 were effective in terms of the growth inhibition of the postharvest yam pathogens $F$. oxysporum and Botryodiplodia theobromae and reduced rot induction in yam tubers by these two pathogens by up to $83 \%$ (Swain et al. 2008). Our findings suggested that applications of $B$. subtilis strains 151B1 and YBC suppressed $F$. solani PF7 infection on passion fruit plants.

Growth inhibition of plant pathogens by Bacillus species may be partly attributed to the production of extracellular enzymes such as chitinase (Swain et al. 2008) or various cyclic lipopeptides (Khan et al. 2017) by these biocontrol bacteria. Such Bacillus-based metabolites could cause damage to the cells of the pathogens and result in the alteration of cell morphologies and structures or in apoptosis and necrosis in a filamentous fungus such as $R$. stolonifer (Gong et al. 2015; Tang et al. 2014). Gong et al. (2015) reported that iturin A and plipastatin A produced by B. amyloliquefaciens strain S76-3 damaged the plasma membranes of $F$. graminearum, in addition to causing distortion and conglobation along the hyphae and inhibiting branch formation and growth (Gong et al. 2015). Another study by Tang et al. (2014) indicated that concentrations of $<50 \mu \mathrm{g} / \mathrm{ml}$ of fengycin produced by $B$. subtilis fmbJ increased levels of apoptosis-associated features in $R$. stolonifer, including chromatin condensation, ROS accumulation, mitochondrial membrane potential depolarization, phosphatidylserine externalization, and occurrence of DNA strand breaks, compared with a control treatment; at high concentrations $(>50 \mu \mathrm{g} / \mathrm{ml})$, fengycin induced

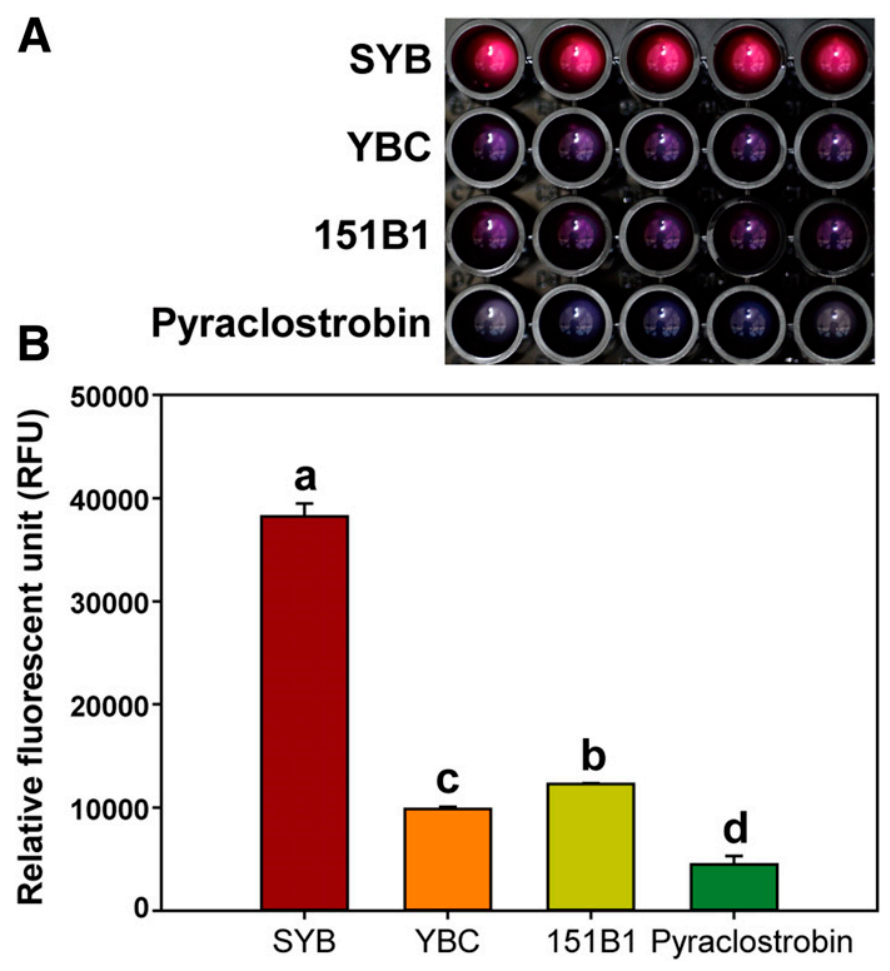

Fig. 8. Effects of culture filtrates from Bacillus subtilis strains YBC and 151B1 on energy metabolism of Fusarium solani PF7. A, The image shows the colorimetric change of the Alamar blue indicator with each treatment. B, Relative fluorescent units (RFUs) of each treatment. SYB broth, pyraclostrobin (at a concentration of $202.8 \mu \mathrm{M}$ ), and culture filtrates from B. subtilis YBC and 151B1 were applied at equal volume to the conidial suspensions of F. solani $\mathrm{PF} 7\left(1 \times 10^{5}\right.$ conidia/ml $)$. The mixtures were incubated at $25^{\circ} \mathrm{C}$ in the dark for $12 \mathrm{~h}$ and stained with Alamar blue for $1 \mathrm{~h}$. RFUs with each treatment were determined using a Tecan Infinite M200 plate reader with excitation at $570 \mathrm{~nm}$ and emission at $600 \mathrm{~nm}$. Bars labeled with different letters are significantly different according to one-way analysis of variance and the least significant difference test $(P \leq 0.05)$. 
necrosis (Tang et al. 2014). In this study, our data indicated that the respective culture filtrates from $B$. subtilis strains 151B1 and YBC in SYB medium inhibited spore germination and mycelium growth of $F$. solani $\mathrm{PF} 7$ in vivo and on the leaf surfaces of passion fruits and caused conglobation of the germ tubes and hyphal tips. Additionally, at $6 \mathrm{~h}$ of treatment with the culture filtrates from B. subtilis strains $151 \mathrm{~B} 1$ and $\mathrm{YBC}$, the cells of $F$. solani PF7 became permeable to Evans blue stain and exhibited apoptosis-associated features. These findings suggested that the metabolites from B. subtilis strains $151 \mathrm{~B} 1$ and $\mathrm{YBC}$ interfere with the membrane integrity of and induce apoptosis in the collar rot pathogen $F$. solani. However, the effect of metabolites from both Bacillus strains on
F. solani was fungistatic but not fungicidal. Cells at 3- or 6-h treatment with culture filtrates from both Bacillus strains still grew on potato dextrose agar (data not shown). Our data by LC/MS-MS analysis indicated that both $B$. subtilis strains $151 \mathrm{~B} 1$ and YBC produced $\mathrm{C} 14$ and $\mathrm{C} 15$ surfactin-like compounds, whereas only strain 151B1 produced iturin A-like compounds, suggesting that surfactin family lipopeptides may induce apoptosis in $F$. solani. However, the structures of the surfactins produced by $B$. subtilis strains 151B1 and YBC and their roles in the induction of apoptosis remain to be determined.

Changes in mitochondrial membrane potential could play a role in the induction of apoptosis (Ly et al. 2003). Data from Zhang and
A

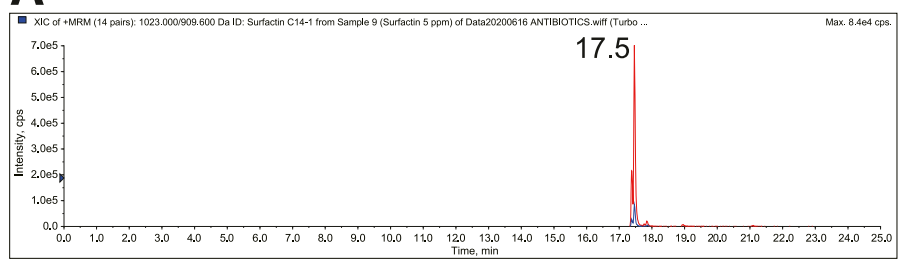

C
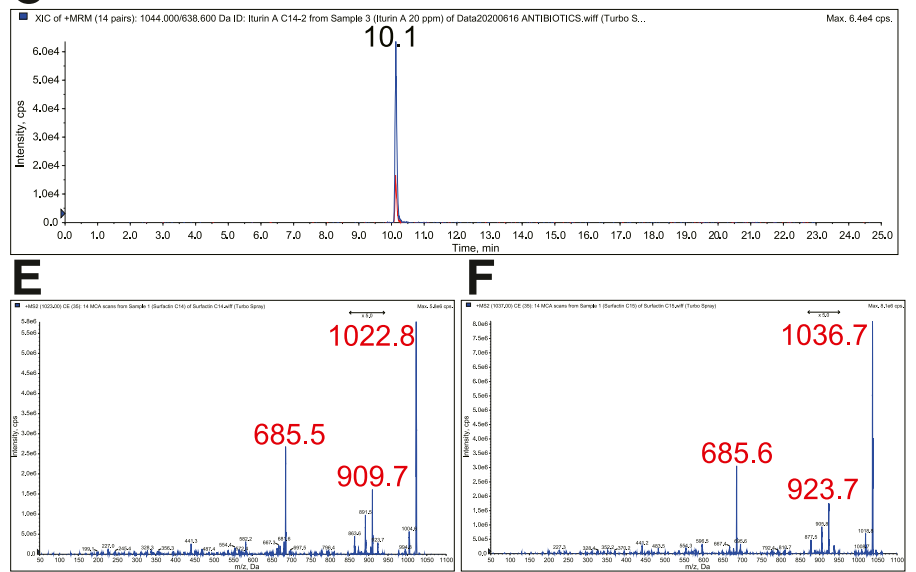

1

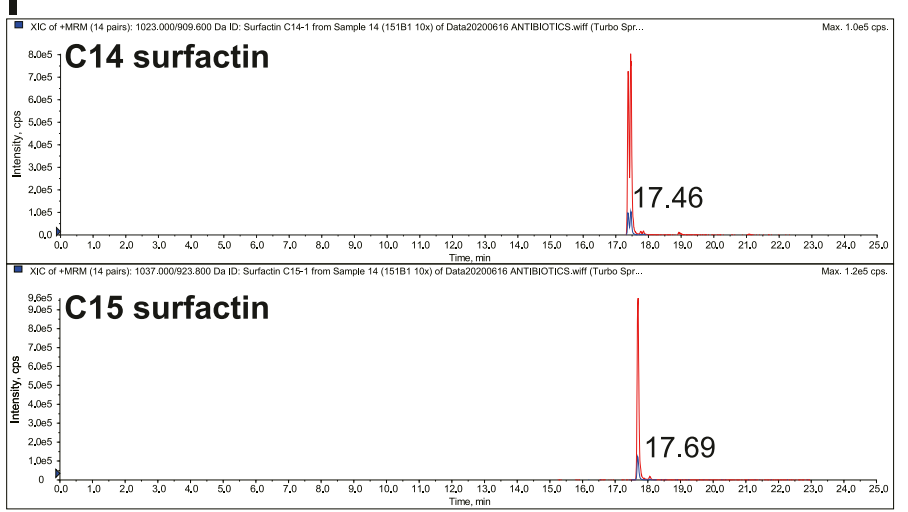

$\mathbf{K}$

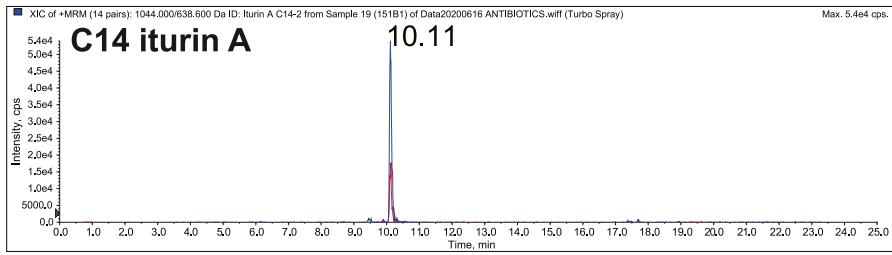

B

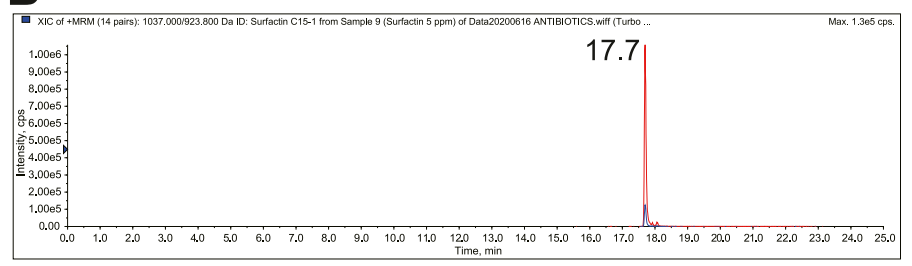

D
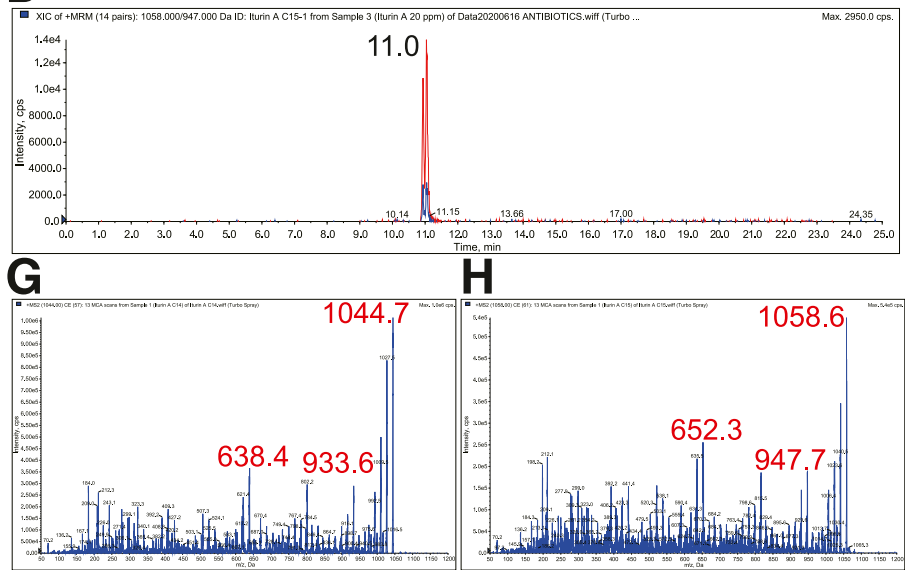

$\mathbf{J}$
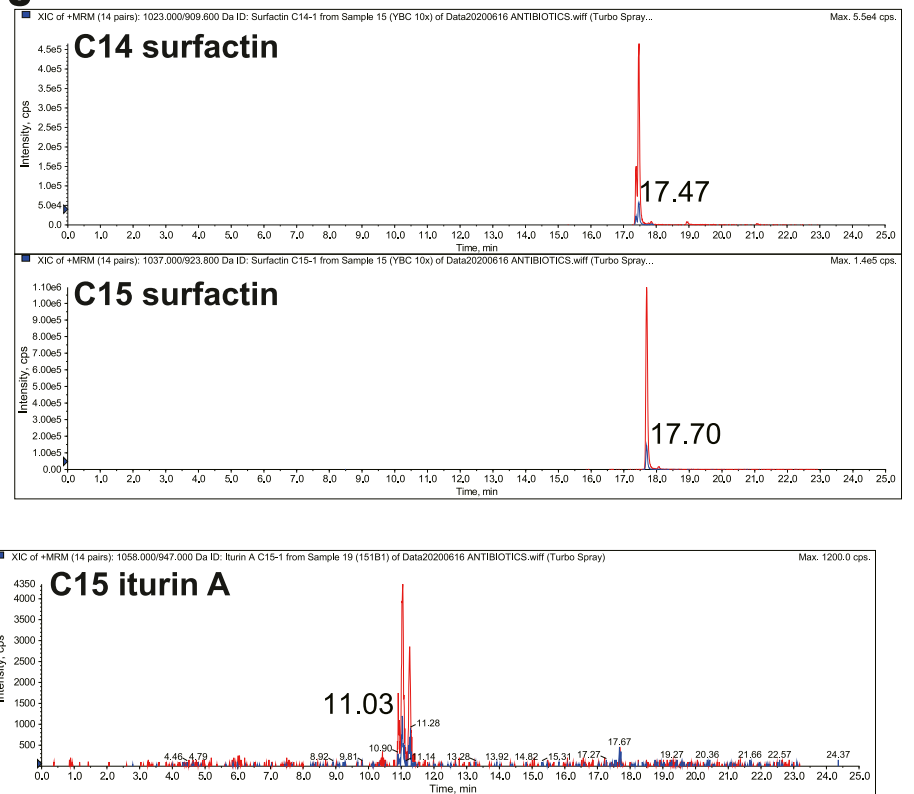

Fig. 9. Liquid chromatography-tandem mass spectrometry chromatogram of surfactin and iturin A family compounds and the respective multiple reaction monitoring (MRM) transitions. Chromatograms for surfactins ( $5 \mathrm{mg} /$ liter) and iturin A standards (20 mg/liter; Sigma-Aldrich) are as follows: A, C14 surfactin, B, C15 surfactin, C, C14 iturin A, and D, C15 iturin A. MRM transitions are shown for E, C14 surfactin, F, C15 surfactin, G, C14 iturin A, and H, C15 iturin A. I, Chromatogram of surfactin family compounds from B. subtilis 151B1. J, Chromatogram of surfactin family compounds from B. subtilis YBC. K, Chromatogram of iturin A family compounds from B. subtilis strain 151B1. 
Sun (2018) demonstrated that fengycin BS155 from B. subtilis reduced mitochondrial membrane potential and induced bursts of ROS and chromatin condensation in rice blast fungus Magnaporthe grisea hyphal cells (Zhang and Sun 2018). In this study, we found by JC-1 staining that mitochondrial membrane potential in $F$. solani PF7 was reduced by treatment with the culture filtrates from B. subtilis strains 151B1 and YBC compared with treatment with SYB medium. Additionally, our results indicated that culture filtrates from $B$. subtilis strains $151 \mathrm{~B} 1$ and YBC acted by not only inducing membrane damage and apoptosis and disrupting membrane potential but also by interfering with energy metabolism in $F$. solani $\mathrm{PF7}$, which was evidenced by the similar results for strain 151B1- and YBC-treated cells to those of the mitochondria complex III quinone outside inhibitor, pyraclostrobin, for the Alamar blue assay.

Induction of systemic resistance by plant-associated Bacillus was demonstrated in various studies and the related literature was broadly reviewed (Shafi et al. 2017; Urra et al. 2013). The surfactin and fengycin lipopeptides synthesized by $B$. subtilis and volatile organic compounds such as 2,3-butendiol were suggested as elicitors for triggering salicylate- and/or jasmonate/ethylenedependent defense mechanisms in plants (Kloepper et al. 2004; Ongena et al. 2007; Ryu et al. 2004). We do not exclude the role of the induction of systemic resistance in disease control because our unpublished results indicated that B. subtilis strain 151B1 enhanced the expression of plant defense genes, including phenylalanine ammonia-lyase $P A L$, peroxidase $P O X$, and pathogenesis-related $P R l a$, in cucumber seedlings after $24 \mathrm{~h}$ of inoculation compared with the water control.

In conclusion, the findings of this study suggest that $B$. subtilis strains $151 \mathrm{~B} 1$ and $\mathrm{YBC}$ are promising biological control agents for collar rot disease caused by $F$. solani in passion fruits. They exhibited preventive and curative control efficacy against the disease in various experiments. Their biocontrol potential is partly attributable to the metabolites produced by the two biocontrol bacteria and to the induction of apoptosis, reduction of mitochondrial membrane potential, and interference with the energy metabolism of $F$. solani that they cause.

\section{ACKNOWLEDGMENTS}

We thank Jenn-Wen Huang and Yi-Hsien Lin for their valuable comments and helpful discussions; and Shang-Shu Yang and Man-Chun Yang (Pesticide Residue Analysis Center, College of Agriculture and Natural Resources, National Chung-Hsing University) for performing the analysis of lipopeptides from $B$. subtilis by LC/MS-MS.

\section{LITERATURE CITED}

Abeysinghe, S. 2007. Biological control of Fusarium solani f. sp. phaseoli the causal agent of root rot of bean using Bacillus subtilis CA32 and Trichoderma harzianum RU01. Ruhuna J. Sci. 2:82-88.

Agriculture and Food Agency. 2018. 2018 Agriculture Statistics Yearbook. Agriculture and Food Agency, Council of Agriculture, Executive Yuan, Taiwan.

Bahar, M., and Shahab, H. 2012. Analysis of Iranian isolates of Fusarium solani using morphological, pathogenicity and microsatellite DNA marker characterization. Afr. J. Biotechnol. 11:474-482.

Bueno, C. J., Fischer, I. H., Rosa, D. D., Firmino, A. C., Harakava, R., Oliveira, C. M. G., and Furtado, E. L. 2014. Fusarium solani f. sp. passiflorae: A new forma speciales causing collar rot in yellow passion fruit. Plant Pathol. 63:382-389.

Chen, C., and Dickman, M. B. 2005. Proline suppresses apoptosis in the fungal pathogen Colletotrichum trifolii. Proc. Natl. Acad. Sci. U.S.A. 102: 3459-3464.

Choudhary, D. K., and Johri, B. N. 2009. Interactions of Bacillus spp. and plants-With special reference to induced systemic resistance (ISR). Microbiol. Res. 164:493-513.

Cox, K. D., Quello, K., Deford, R. J., and Beckerman, J. L. 2009. A rapid method to quantify fungicide sensitivity in the brown rot pathogen Monilinia fructicola. Plant Dis. 93:328-331.
Fischer, I. H., and Rezende, J. A. 2008. Diseases of passion flower (Passiflora spp.). Pest Technol. 2:1-19.

Gong, A.-D., Li, H.-P., Yuan, Q.-S., Song, X.-S., Yao, W., He, W.-J., Zhang, J.-B., and Liao, Y.-C. 2015. Antagonistic mechanism of iturin A and pipastatin A from Bacillus amyloliquefaciens S76-3 from wheat spikes against Fusarium graminearum. PLoS One 10:e0116871.

Honraet, K., De Vos, M., Summerbell, R., Van Kempen, I., De Saeger, S., Vermeersch, H., Van Peteghem, C., and Nelis, H. 2005. Recurrent colonization of successively implanted tracheoesophageal vocal prostheses by a member of the Fusarium solani species complex. J. Clin. Microbiol. 43: 770-777.

Huang, T.-P., Tzeng, D. D.-S., Wong, A. C., Chen, C.-H., Lu, K.-M., Lee, Y.-H., Huang, W.-D., Hwang, B.-F., and Tzeng, K.-C. 2012. DNA polymorphisms and biocontrol of Bacillus antagonistic to citrus bacterial canker with indication of the interference of phyllosphere biofilms. PLoS One 7: e42124.

Khan, N., Maymon, M., and Hirsch, A. M. 2017. Combating Fusarium infection using Bacillus-based antimicrobials. Microorganisms 5:75.

Kim, S., Kim, J. Y., Kim, S.-H., Bae, H. J., Yi, H., Yoon, S. H., Koo, B. S., Kwon, M., Cho, J. Y., Lee, C.-E., and Hong, S. 2007. Surfactin from $\mathrm{Ba}$ cillus subtilis displays anti-proliferative effect via apoptosis induction, cell cycle arrest and survival signaling suppression. FEBS Lett. 581:865-871.

Kloepper, J. W., Ryu, C.-M., and Zhang, S. 2004. Induced systemic resistance and promotion of plant growth by Bacillus spp. Phytopathology 94:1259-1266.

Lee, W. L., and Lin, J. K. 2008. The cultivation and management of passion fruits. Taiwan Agric. Res. Inst. Tech. Serv. Q. Bull. 19:4-8.

Leslie, J. F., and Summerell, B. A. 2008. The Fusarium Laboratory Manual. Blackwell, Ames, IA.

Lugtenberg, B., and Kamilova, F. 2009. Plant-growth-promoting rhizobacteria. Annu. Rev. Microbiol. 63:541-556.

Ly, J. D., Grubb, D. R., and Lawen, A. 2003. The mitochondrial membrane potential $\left(\Delta \psi_{\mathrm{m}}\right)$ in apoptosis; an update. Apoptosis 8:115-128.

Martin, F. W., and Nakasone, H. Y. 1970. The edible species of Passiflora. Econ. Bot. 24:333-343.

Mnif, I., Hammami, I., Triki, M. A., Azabou, M. C., Ellouze-Chaabouni, S., and Ghribi, D. 2015. Antifungal efficiency of a lipopeptide biosurfactant derived from Bacillus subtilis SPB1 versus the phytopathogenic fungus, Fusarium solani. Environ. Sci. Pollut. Res. 22:18137-18147.

Ongena, M., and Jacques, P. 2008. Bacillus lipopeptides: Versatile weapons for plant disease biocontrol. Trends Microbiol. 16:115-125.

Ongena, M., Jourdan, E., Adam, A., Paquot, M., Brans, A., Joris, B., Arpigny, J.-L., and Thonart, P. 2007. Surfactin and fengycin lipopeptides of Bacillus subtilis as elicitors of induced systemic resistance in plants. Environ. Microbiol. 9:1084-1090.

Reers, M., Smiley, S. T., Mottola-Hartshorn, C., Chen, A., Lin, M., and Chen, L. B. 1995. Mitochondrial membrane potential monitored by JC-1 dye. Methods Enzymol. 260:406-414, IN1-IN3, 415-417.

Ryu, C.-M., Farag, M. A., Hu, C.-H., Reddy, M. S., Kloepper, J. W., and Paré, P. W. 2004. Bacterial volatiles induce systemic resistance in Arabidopsis. Plant Physiol. 134:1017-1026.

Sarwar, A., Hassan, M. N., Imran, M., Iqbal, M., Majeed, S., Brader, G., Sessitsch, A., and Hafeez, F. Y. 2018. Biocontrol activity of surfactin A purified from Bacillus NH-100 and NH-217 against rice bakanae disease. Microbiol. Res. 209:1-13.

Shafi, J., Tian, H., and Ji, M. 2017. Bacillus species as versatile weapons for plant pathogens: A review. Biotechnol. Biotechnol. Equip. 31:446-459.

Sneath, P. H. A., Mair, M. E., and Holt, J. G. 1986. Bergey's Manual of Systematic Bacteriology. Williams and Wilkins, Baltimore, MD.

Ssekyewa, C., Opio, A. F., Swinburne, T. R., Van Damme, P. L. J., and Abubakar, Z. M. 1999. Sustainable management of collar rot disease of passion fruits in Uganda. Int. J. Pest Manage. 45:173-177.

Sundaramoorthy, S., Raguchander, T., Ragupathi, N., and Samiyappan, R. 2012. Combinatorial effect of endophytic and plant growth promoting rhizobacteria against wilt disease of Capsicum annum L. caused by Fusarium solani. Biol. Control 60:59-67.

Swain, M. R., Ray, R. C., and Nautiyal, C. S. 2008. Biocontrol efficacy of Bacillus subtilis strains isolated from cow dung against postharvest yam (Dioscorea rotundata L.) pathogens. Curr. Microbiol. 57:407-411.

Tang, Q., Bie, X., Lu, Z., Lv, F., Tao, Y., and Qu, X. 2014. Effects of fengycin from Bacillus subtilis fmbJ on apoptosis and necrosis in Rhizopus stolonifer. J. Microbiol. 52:675-680.

Turner, J. A. 2020. The Online Pesticide Manual. British Crop Production Council, Hampshire, UK.

Urra, F. A., Córdova-Delgado, M., Pessoa-Mahana, H., Ramírez-Rodríguez, O., Weiss-López, B., Ferreira, J., and Araya-Maturana, R. 2013. Mitochondria: A promising target for anticancer alkaloids. Curr. Top. Med. Chem. 13:2171-2183.

Weisburg, W. G., Barns, S. M., Pelletier, D. A., and Lane, D. J. 1991. 16S ribosomal DNA amplification for phylogenetic study. J. Bacteriol. 173:697-703. 
White, T. J., Bruns, T., Lee, S., and Taylor, J. 1990. Amplification and direct sequencing of fungal ribosomal RNA genes for phylogenetics. Pages 315-322 in: PCR Protocols, A Guide to Methods and Applications. M. A. Innis, D. V. Gelfand, J. J. Sninsky, and T. J. White, eds. Academic Press, New York.

Yamamoto, S., and Harayama, S. 1995. PCR amplification and direct sequencing of gyrB genes with universal primers and their application to the detection and taxonomic analysis of Pseudomonas putida strains. Appl. Environ. Microbiol. 61:1104-1109.
Zalila-Kolsi, I., Ben Mahmoud, A., Ali, H., Sellami, S., Nasfi, Z., Tounsi, S., and Jamoussi, K. 2016. Antagonist effects of Bacillus spp. strains against Fusarium graminearum for protection of durum wheat (Triticum turgidum L. subsp. durum). Microbiol. Res. 192:148-158.

Zhang, L., and Sun, C. 2018. Fengycins, cyclic lipopeptides from marine Bacillus subtilis strains kill the plant-pathogenic fungus Magnaporthe grisea by inducing reactive oxygen species production and chromatin condensation. Appl. Environ. Microbiol. 84:e00445-e00418. 